\title{
Evolution Characteristics Analysis of Pressure-Arch of a Highway Tunnel under Different Stress Conditions
}

\author{
S. R. Wang ${ }^{1,2^{*}}$, Y. G. Wang ${ }^{2}$, C. L. Li ${ }^{2}$, Z. S. Zou ${ }^{1}$ and F. Cui ${ }^{1}$

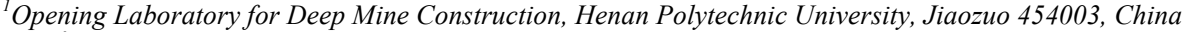 \\ ${ }^{2}$ School of Civil Engineering and Mechanics, Yanshan University, Qinhuangdao 066004, China \\ ${ }^{3}$ Institute of Urban Construction, Hebei Normal University of Science \& Technology, Qinhuangdao 066004, China
}

Received 8 March 2016; Accepted 25 June 2016

\begin{abstract}
It is very important for an engineer to understand the evolution characteristics of pressure-arch of a highway tunnel under different stress conditions. After the numerical model of the highway tunnel being built, considering the lateral pressure coefficients varied from small to large, the forming process, distributional pattern and evolution characteristics of the pressure-arch of the highway tunnel under different stress states were analyzed. The numerical simulation of the step-bystep excavation was carried out along the tunnel axis, the distribution morphology and variation characteristics of the pressure-arches located in the front of working face and roof and floor of the tunnel during excavation were revealed. The results showed that the pressure-arch shapes of the tunnel mainly varied from spire, flat, convex, to sag top with the lateral pressure coefficient from small to large. And the stability of the surrounding rock near the tunnel working face became worse and worse with the principal stress difference increasing. The results are of great significance for the construction and reinforcing design of the similar engineering practice.
\end{abstract}

Keywords: Highway Tunnel, Surrounding Rock, Pressure-arch, Stress State, Stability

\section{Introduction}

After a highway tunnel being excavated, the stress state of the surrounding rock in the excavation face changes from three-dimensional to two-dimensional stress state. With the secondary stress state of the surrounding rock of the tunnel self-adjustment, the radial stress gradually increases from zero on the free face to the original stress in the deep of the surrounding rock, and after the tangential stress experiences a peak value, gradually changes to the original stress of the surrounding rock. The stress state is constantly adjusted by itself to resist the uneven deformation of the surrounding rock and finally the stress concentration area forms in the surrounding rock, which is known as the pressure-arch.

During the construction process of all kinds of tunnels, the safe and efficient construction and lower support costs of a tunnel project are of great importance. Therefore, it is of the practical value to confirm and reveal the distribution morphology and the evolution characteristics of pressurearch of the tunnel and make full use of the self-bearing capacity of the tunnel surrounding rock.

\section{State of the Art}

The forming process and evolution characteristics of the pressure-arch of a tunnel have received wide attention of

\footnotetext{
*E-mail address: w_sr88@163.com ISSN: 1791-2377 @ 2016 Eastern Macedonia and Thrace Institute of Technology. All rights reserved.
}

scholars and professionals in the world. For examples, Polillo et al. conducted a sand arching experiment on a similar well configuration, observed the effect of well excavation on the stability of the surrounding sand [1]. Goel et al. found the tunnel size effect on the support pressure was significant in flat-roofed underground openings, and suggested two equations for the associated support pressure estimation [2]. Prokhorov found that the arch effect in a cylindrical caused loosely packed interior region was proved by a large cylindrical alumina pressing experiment [3]. Hashash et al. discussed the soil arching effect and presented a detailed interpretation of the stress evolution around a braced excavation [4]. Shahin et al. carried out threedimensional model tests and the corresponding numerical analysis to investigate the influences of tunnel excavation on surface settlement and earth pressure surrounding a tunnel [5]. Hernández-Montes et al. addressed the influence of equilibrium, creep, and shrinkage as they affected the design of the buried arches from a theoretical perspective [6]. Li proposed that the unstable section of the stope should be reinforced with bolt-shotcrete ribs based on the pressure arch in the failed rock [7]. Poulsen conducted coal pillar load calculation by pressure arch theory and near field extraction ratio [8]. Kim et al. found that the lateral earth pressure decreased within active displacement of wall during deep excavation and the arching effect was more significant comparing to shallow excavation by using experimental tests [9].

Chinese scholars Liu et al. measured the distribution of stress in the wall rock mass with earth-pressure cell during the tunnel excavation and suggested an innovated rock mass pressure release rate idea [10]. Zhu et al. analyzed the construction sequence optimization and supporting structure 
of shallow multi-arch tunnel under unsymmetrical pressure conditions [11]. Chen et al. developed a three-dimensional numerical simulation model to gain understanding of adjustment of tunneling stress [12]. Jiang et al. analyzed the earth pressure acting on the shield tunnel lining and the soil arching effects due to tunneling [13]. Wang et al. not only revealed the geometry of the pressure arch and its mechanical evolution characteristics, but also analyzed the mechanical stability and instability failure modes of the pressure-arch through a highway tunnel [14]. Li et al. analyzed the supporting structure of pressure to small spacing shallow bias tunnel in soft rock by testing a typical section in the field [15]. Sun et al. discussed the affecting factors of soil arching by the theoretical analysis method and the experimental method [16]. Xing et al. carried out the changes law of the soil arch under different support action through measuring radial and circumferential pressure data of soil around the tunnel under different support forces [17].

In a word, although some achievements on the research of pressure-arch of the surrounding rock of the tunnel have been obtained, some studies such as the arching conditions, the mechanics evolution process and the stress states influence to the pressure-arch, have not yet formed a scientific and mature theoretical system, and more researchers need to deepen this study. Therefore, combining with the practical engineering, it is necessary to study the pressure transformation law, the arching form and the threedimensional evolution characteristics of the pressure-arch.

The reminder of this paper is organized as follows: Section 3 establishes the computational model and points out the research contents. Section 4 discusses and analyzes the results. Section 5 summarizes the conclusions.

\section{Methodology}

\subsection{The Computational Model}

The dimensions of the cross-section of a highway tunnel are $24 \mathrm{~m}$ wide and $13 \mathrm{~m}$ high, the surrounding rock is mainly composed of weathered sandstone, and the stability of surrounding rock is poor. The hydro-geological conditions of the tunnel surrounding rock are simple.

As shown in Fig. 1, the computational model of tunnel was built using FLAC ${ }^{3 \mathrm{D}}$ at depth of $80 \mathrm{~m}$ underground under the hydro-static stress state. The dimensions of the model were $80 \mathrm{~m}$ long, $2 \mathrm{~m}$ wide and $64 \mathrm{~m}$ high separately in the $x$ ,$y$-, and $z$-axis directions. The model was divided into 10048 elements. The horizontal displacements of four lateral boundaries of the model were restricted, and its bottom was fixed. The vertical load was applied to the model top, which was equal to the weight converted from the overburden thickness in value. The material strength of the model was supposed to meet the Mohr-Coulomb criterion, and the calculation parameters were selected as listed in Table 1 .

On the other hand, the three-dimension model was 120 $\mathrm{m}$ long, $100 \mathrm{~m}$ wide and $103 \mathrm{~m}$ high, and it was divided into 42000 elements by using FLAC ${ }^{3 D}$. The lateral boundaries of the model were restricted, and its bottom was fixed. The upper surface was the load boundary, on which the vertical load was applied to simulate the weight of the overburden 80 $\mathrm{m}$ uniform loads. The material strength of model was supposed to meet the Mohr-Coulomb criterion, and moreover, it was supposed that the model was in the hydrostatic stress state, namely the lateral pressure coefficient $\lambda$ was 1.0 .

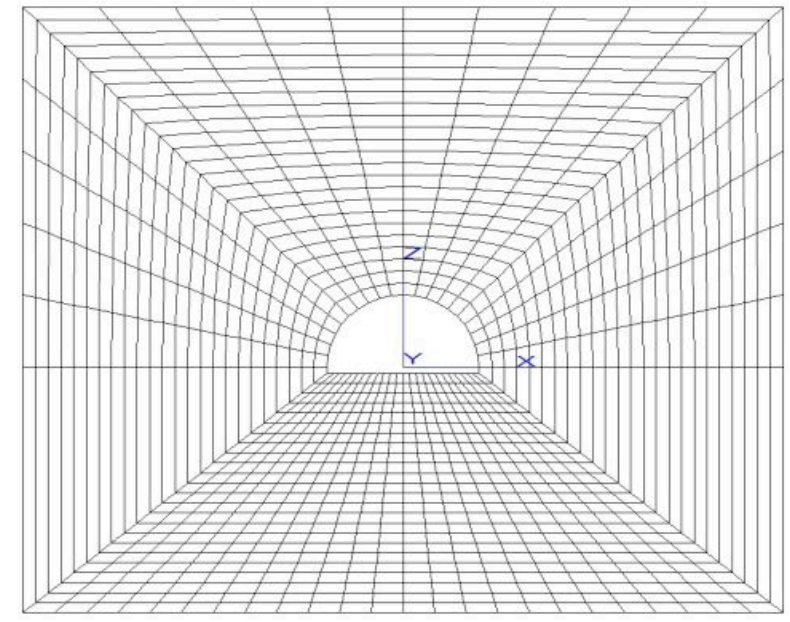

Fig.1. The computational model and its meshing

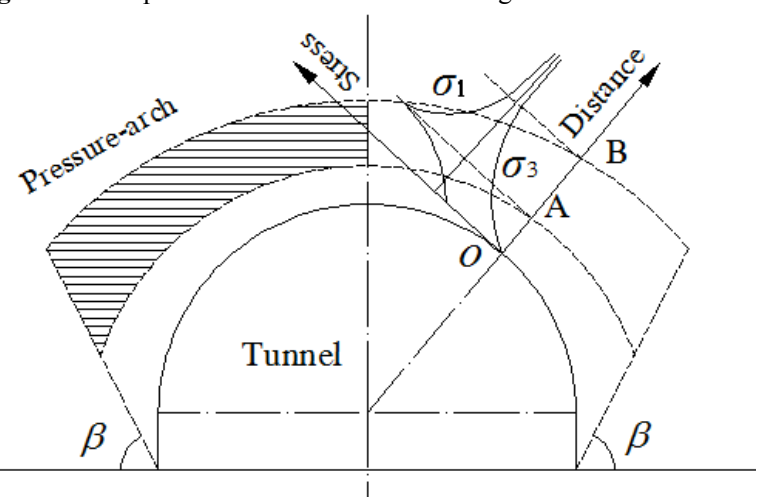

Fig.2. Schematic pressure-arch and its boundaries

Table 1. Calculation parameters of the surrounding rock of the tunnel

\begin{tabular}{|c|c|c|c|c|c|}
\hline $\begin{array}{l}\text { Density } \\
\left(\mathrm{kg} / \mathrm{m}^{3}\right)\end{array}$ & $\begin{array}{c}\text { Elastic modulus } \\
(\mathrm{GPa})\end{array}$ & $\begin{array}{c}\text { Poisson } \\
\text { ratio }\end{array}$ & $\begin{array}{l}\text { Cohesion } \\
\text { (MPa) }\end{array}$ & $\begin{array}{c}\text { Friction angle } \\
\left({ }^{\circ}\right)\end{array}$ & $\begin{array}{l}\text { Tension } \\
\text { (MPa) }\end{array}$ \\
\hline 2300 & 5.00 & 0.32 & 1.20 & 33 & 0.50 \\
\hline
\end{tabular}

\subsection{Boundary Definition of Pressure-arch}

In order to facilitate the study, the element stress variable $e$ is defined

$e=\frac{\sigma_{1}-\sigma_{3}}{\sigma_{1}} \times 100 \%$

where $\sigma_{1}$ and $\sigma_{3}$ are the maximum and the minimum principal stress of the calculation unit after the tunnel being excavated.

As shown in Fig. 2, the boundary corresponding to the peak of the maximum principal stress, is defined as the inner boundary of the pressure-arch, and the boundary corresponding to the stress variable $e$ reaches $10 \%$ is defined as the outer boundary of the pressure-arch.

It starts from double-arch feet, the rupture angle developing in both sides of the tunnel surrounding rock, intersecting with pressure-arch of the inner and outer boundaries, which is regarded as the pressure-arch lateral boundary. According to Protodyakonov's theory, the rock rupture angle is $\beta=45^{\circ}+\frac{\varphi}{2}$ as shown in Fig. 1 , where $\varphi$ is the inner friction angle of the surrounding rock. 


\subsection{Numerical Analysis Schemes}

To reveal the pressure-arch evolution characteristics of a highway tunnel, the numerical analysis schemes were conducted according to the following procedures:

Firstly, the computational model was built as a plane problem to carry out the evolution process analysis of the pressure-arch perpendicular to the tunnel axis under different stress states.

Secondly, the three-dimension model was built to study the distribution characteristics of the pressure-arch along the tunnel axis under hydro-static stress state.

Finally, the distribution characteristics of the pressurearch along the tunnel axis were analyzed under different stress states.

\section{Results and Discussion}

\subsection{Pressure-arch Evolution Characteristics under Different Stress States}

As shown in Figs. 3, 4, 5, 6, 7, 8, and 9, when $\lambda=0.25$, the tensile stress appeared on the top of the tunnel, and the pressure-arch only formed in the local region, showing a discontinuous distribution pattern. When $\lambda=0.34$, the pressure-arch was thin slightly convex at the top of the tunnel, and obviously convex on both sides, which showing butterfly-shaped distribution patterns. When $\lambda=0.72$, the pressure-arch showed the vaulted characteristic, which was a part of parabola. When $\lambda=1.0$, the surrounding rock of tunnel is in hydro-static stress state, the pressure-arch appeared evenly in range of the rupture angle. With the $\lambda$ increase gradually, the pressure-arch was compressed in the horizontal direction, the pressure-arch overall showed upward convex. When $\lambda=1.7$, the vault of the pressure-arch was slightly sunken, showing a bimodal distribution pattern.

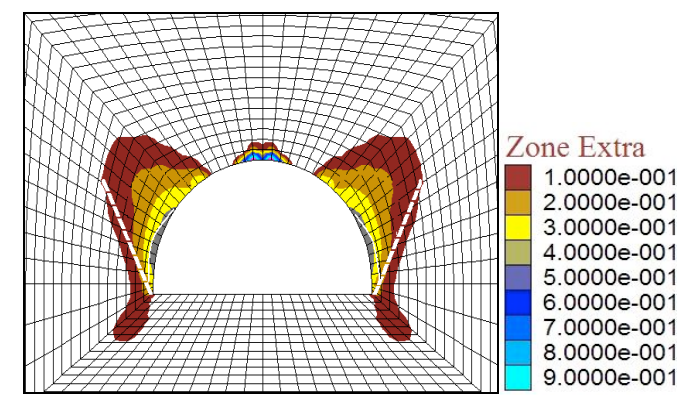

(a) The stress contour of pressure-arch

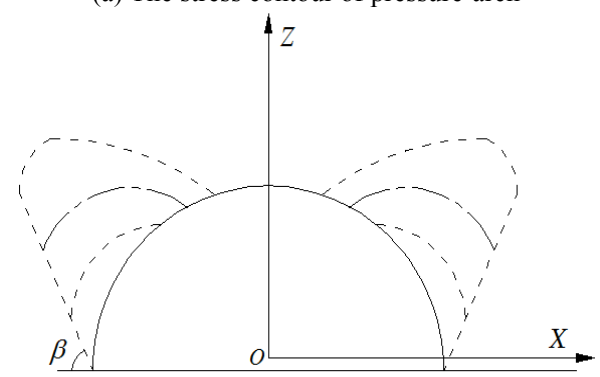

(b) The simplified figure of pressure-arch

Fig.3. Pressure-arch boundary when $\lambda=0.25$

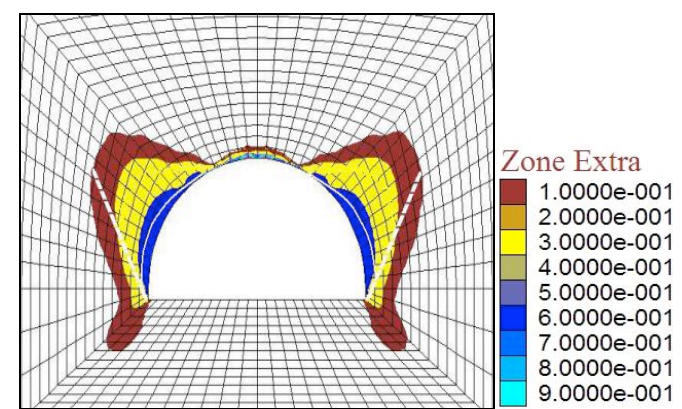

(a) The stress contour of pressure-arch

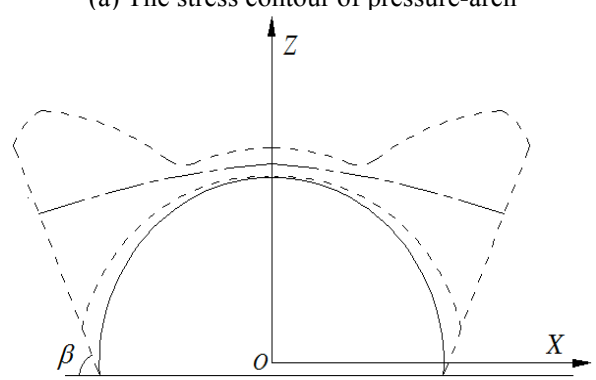

(b) The simplified figure of pressure-arch

Fig.4. Pressure-arch boundary when $\lambda=0.34$

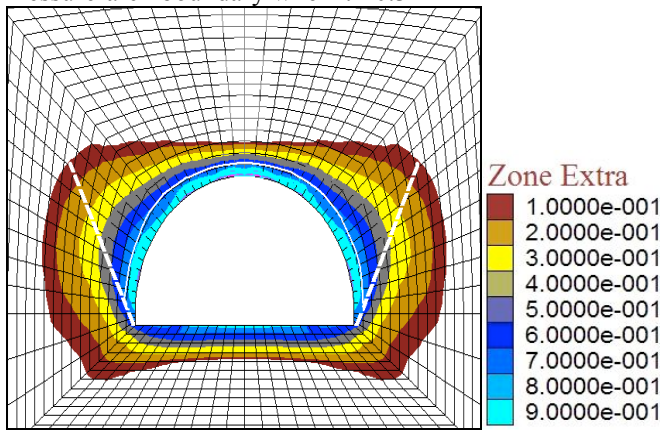

(a) The stress contour of pressure-arch

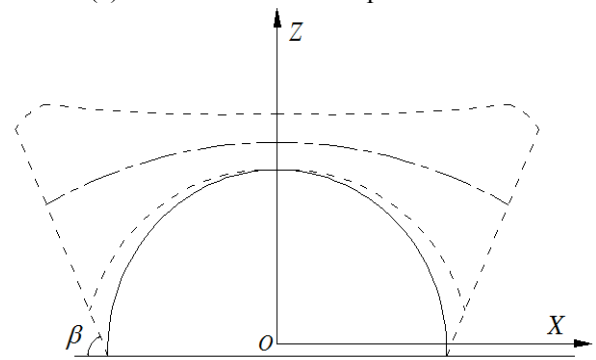

(b) The simplified figure of pressure-arch

Fig.5. Pressure-arch boundary when $\lambda=0.72$

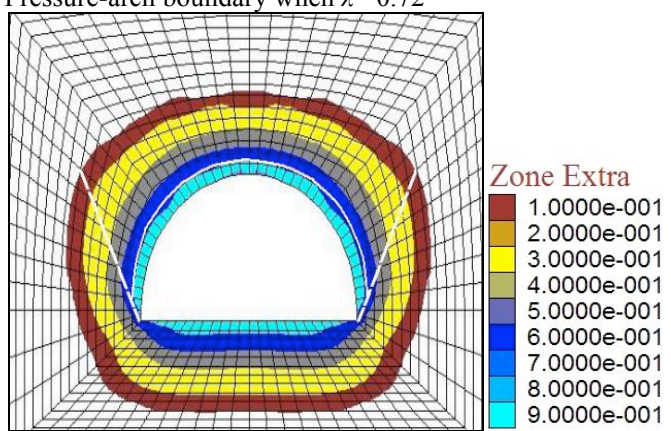

(a) The stress contour of pressure-arch 


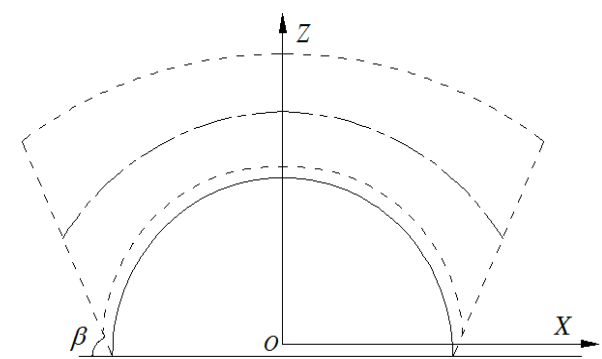

(b) The simplified figure of pressure-arch

Fig.6. Pressure-arch boundary when $\lambda=1.00$

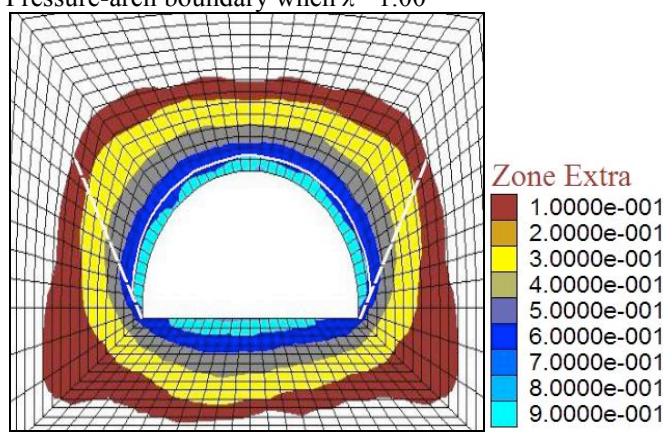

(a) The stress contour of pressure-arch

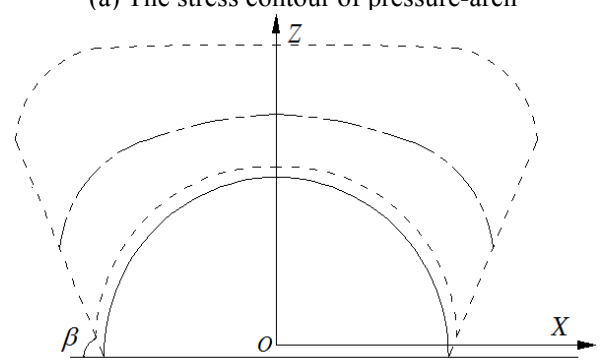

(b) The simplified figure of pressure-arch

Fig.7. Pressure-arch boundary when $\lambda=1.30$

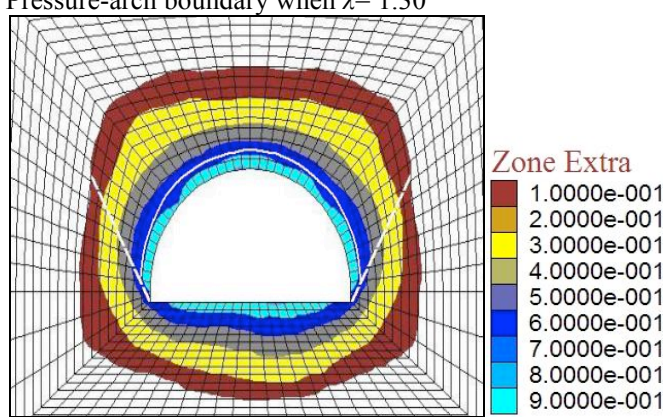

(a) The stress contour of pressure-arch

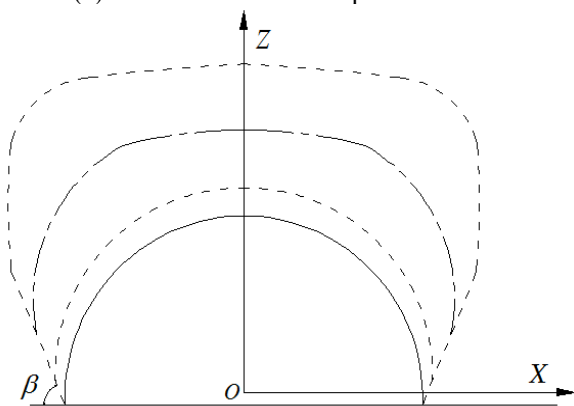

(b) The simplified figure of pressure-arch

Fig.8. Pressure-arch boundary when $\lambda=1.50$

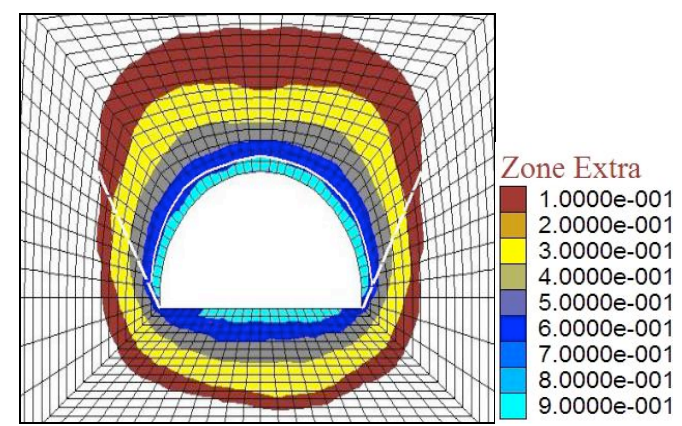

(a) The stress contour of pressure-arch

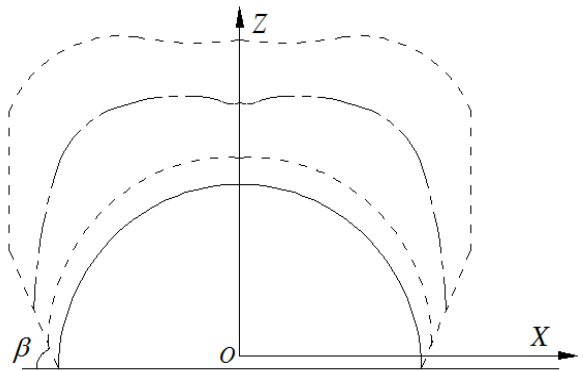

(b) The simplified figure of pressure-arch

Fig.9. Pressure-arch boundary when $\lambda=1.70$

As shown in Fig. 10a, when $0.34<\lambda<1$, with the value of $\lambda$ decreasing, the shape of pressure-arch gradually changed from spire arch to flat arch, and the axis of pressure-arch gradually lowered, i.e. the position of the pressure-arch moved downward overall. As shown in Fig. $10 \mathrm{~b}$, when $\lambda>1$, with the value of $\lambda$ increasing, the shape of pressure-arch changed from upward convex to sag, and the pressure-arch axis gradually rose up, i.e., the position of the pressure-arch overall moved upward, then got away from the excavation face of the tunnel, and the pressure-arch foot was more and more close to the edge of the tunnel. When $\lambda=1.7$, the axis of the pressure-arch showed sag at the top of the arch, and the overall shape of arch showed a bimodal distribution.

In summary, when $\lambda<0.34$, since the tensile stress appeared, the pressure-arch could not be formed at the top of the tunnel, and two local pressure-arch zones formed on both sides of the tunnel; when $0.34<\lambda<1$, the pressure zone of the surrounding rock at the top of the tunnel gradually expanded and showed a flat arch shape; when $\lambda>1$, the pressure-arch of the tunnel showed upward convex, and when $\lambda$ reached a certain level, the arch vault appeared sag, and the pressure-arch axis showed a bimodal distribution pattern.

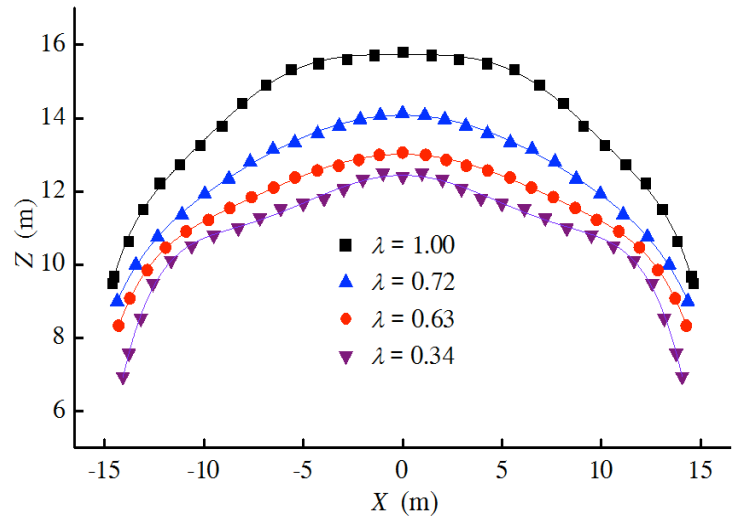

(a) $\lambda<1.0$ 


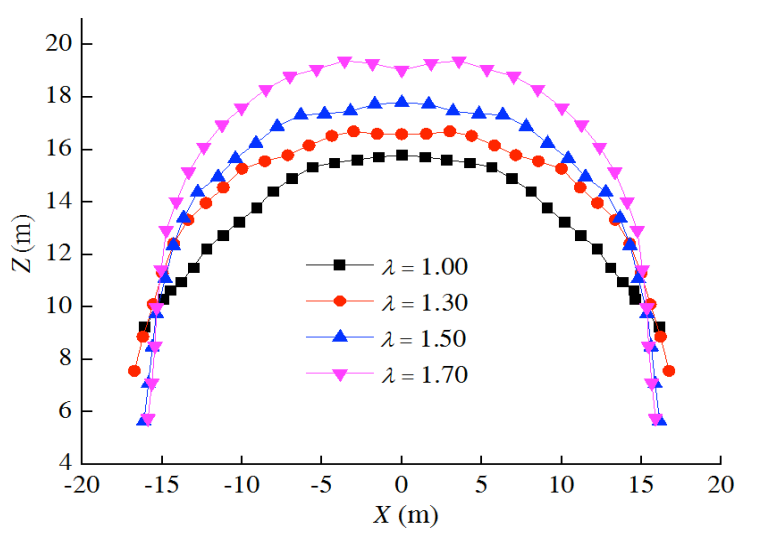

(b) $\lambda>1.0$

Fig.10. The change trend of pressure-arch with $\lambda$

\subsection{Pressure-arch Distribution Characteristics Along $Y$ -} Axis under Hydro-static Stress State

As shown in Fig. 11, when $\lambda=1.0$, with the tunnel excavation length variation from $6 \mathrm{~m}, 12 \mathrm{~m}$ to $18 \mathrm{~m}$, the pressure-arch of the tunnel extended outwards and thickened gradually in front of the working face, the pressure-arch at the top of the working surface developed obliquely upward with a wedgeshaped bulge, gradually thickened and the peak value appeared. The sag morphology of the pressure-arch at the bottom of the working surface is more and more obvious. So the distribution morphology of the pressure-arch near the working face is non-uniform outward expansion (The white line is the inner boundary of the pressure-arch).
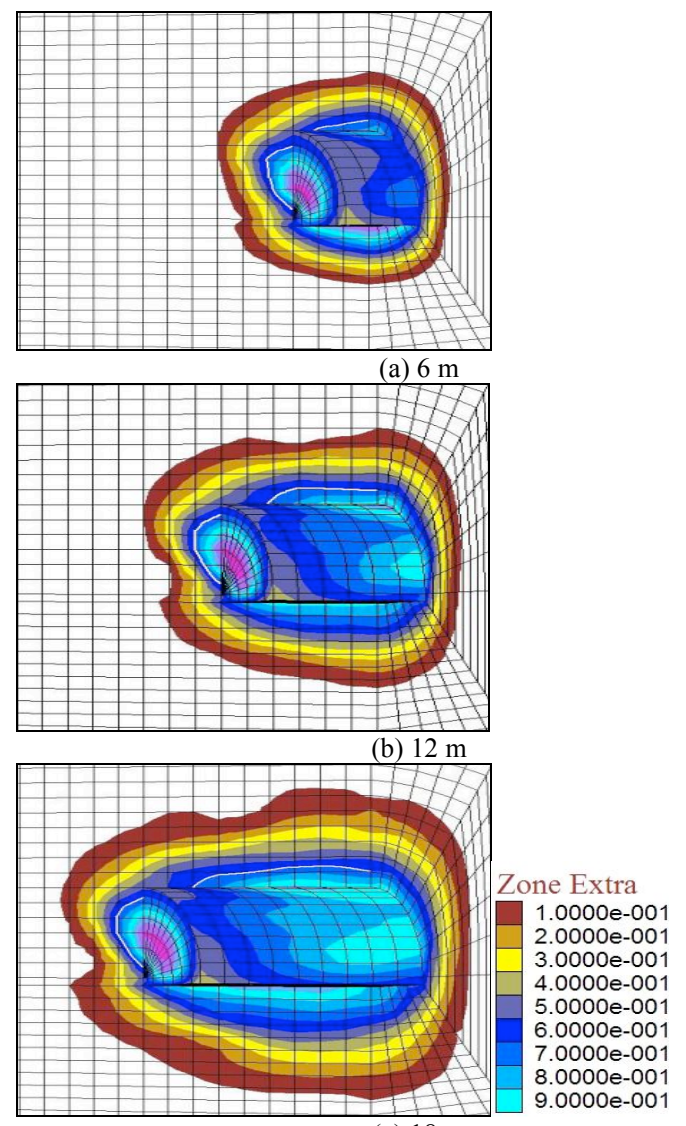

(c) $18 \mathrm{~m}$

Fig.11. Pressure-arch distribution with different excavation length along tunnel axis

With the variation of excavation length from $6 \mathrm{~m}, 12 \mathrm{~m}$ to $18 \mathrm{~m}$ (Fig. 12), the difference values between the maximum and the minimum principal stress of the unit near the tunnel working face gradually increased, and the shear stress $\tau_{\max }$ characterized the difference of the principal stress of the unit was

$$
\tau_{\max }=\frac{\sigma_{1}-\sigma_{3}}{2}
$$

Thus, the shear stress concentration degree near the tunnel working face increased gradually with the excavation length of the tunnel increasing, in other words, the instability of the surrounding rock near the tunnel working face tended to be intensified.

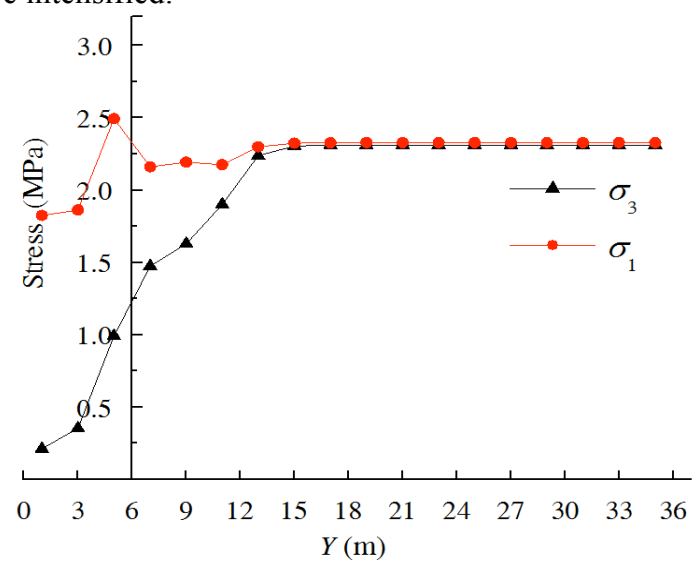

(a) $6 \mathrm{~m}$
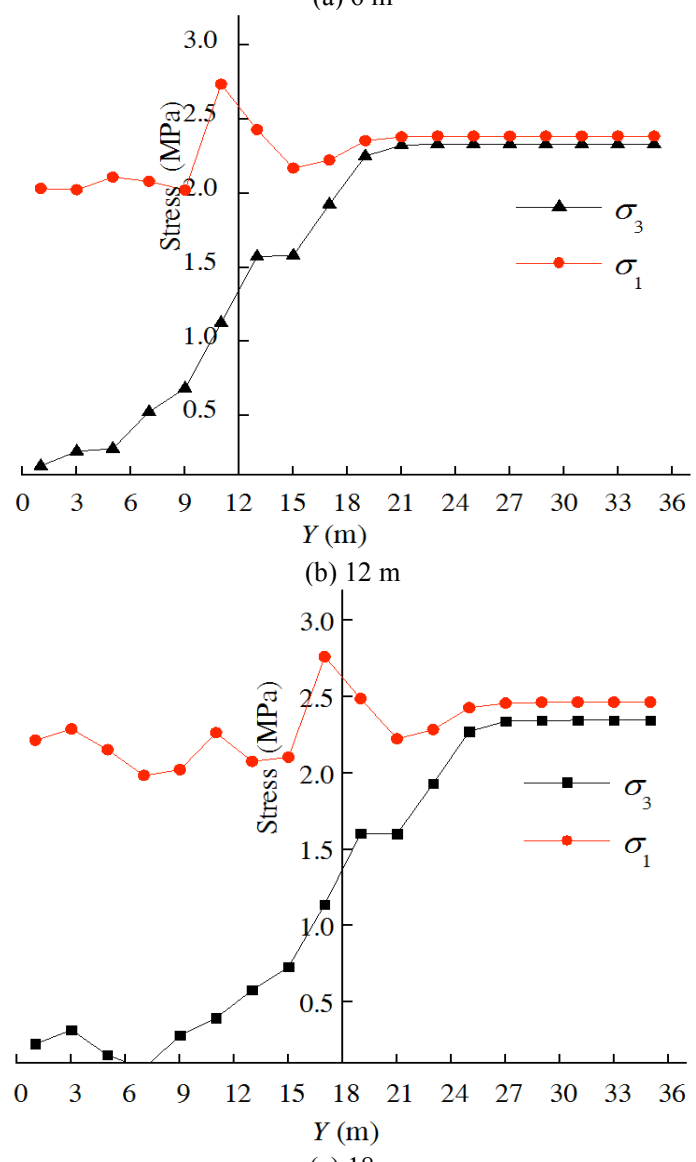

(c) $18 \mathrm{~m}$

Fig.12. Pressure-arch distribution with different excavation length along tunnel axis 
4.3 Pressure-arch Distribution Characteristics Along $Y$ Axis under Different Stress States

As shown in Fig. 13, when $\lambda<1.0$, above the working face of the tunnel the pressure-arch uplifted, showing a wedgeshape distribution, the pressure-arch of the horizontal direction became thick, the sunken shape of the pressurearch on the bottom of the tunnel was obvious, and behind the working face the top of pressure-arch became thin. When $\lambda>1.0$, the pressure-arch on the roof of the tunnel working face uplifted, showing an asymmetrical shape of bimodal distribution, and the pressure-arch in the horizontal direction became thin. The pressure-arch of the tunnel floor appeared sunken, and the pressure-arch of the roof behind the working face became thick. When $\lambda=1.0$, the distribution morphology of the pressure-arch was between the above two cases.

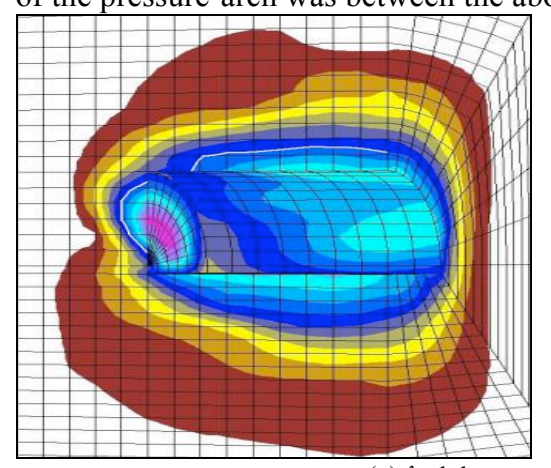

(a) $\lambda=1.1$

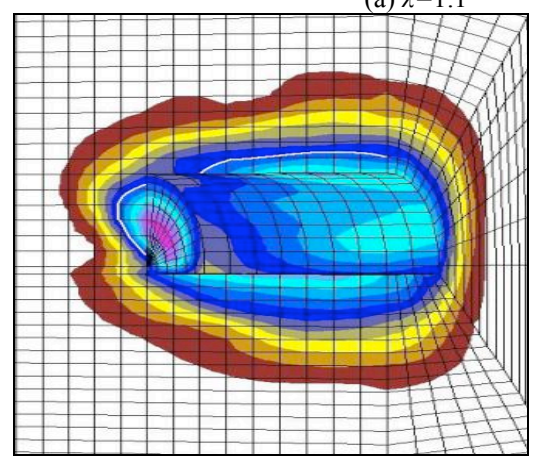

(b) $\lambda=1.0$

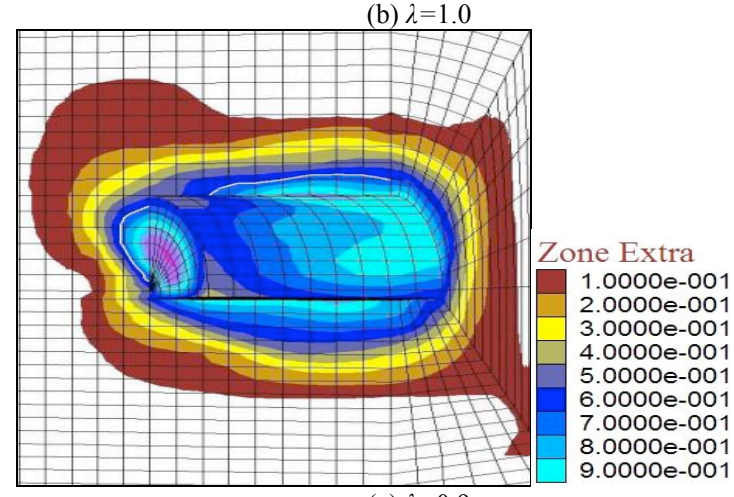

(c) $\lambda=0.9$

Fig.13. Pressure-arch distribution along $\mathrm{Y}$-axis under different stress states

The pressure-arch on the cross-section of the tunnel was shown in Fig. 14. When $\lambda<1.0, \lambda=1.0$, and $\lambda>1.0$, the pressure-arch displayed from the pointed-arch, the domed arch, to the flat arch. When $\lambda=1.0$, the shape of the pressurearch was the most regular, and its range was minimum.

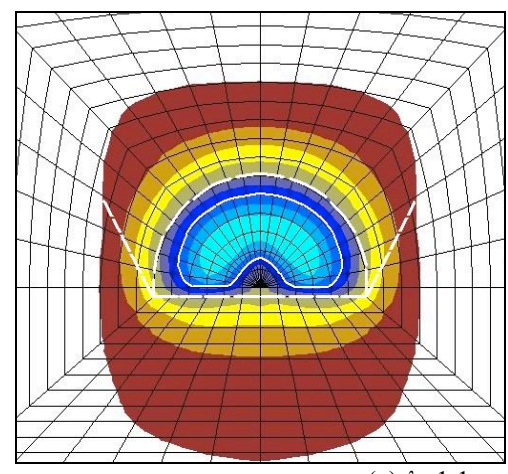

(a) $\lambda=1.1$

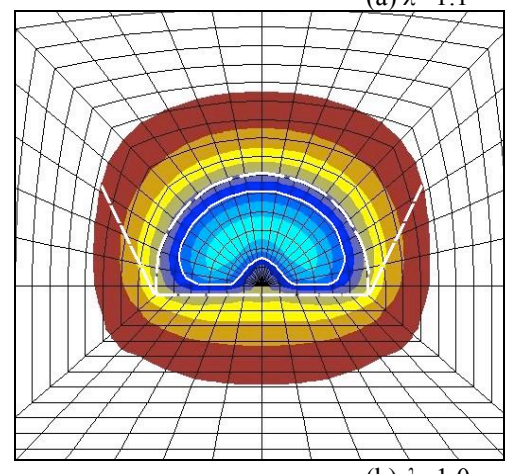

(b) $\lambda=1.0$

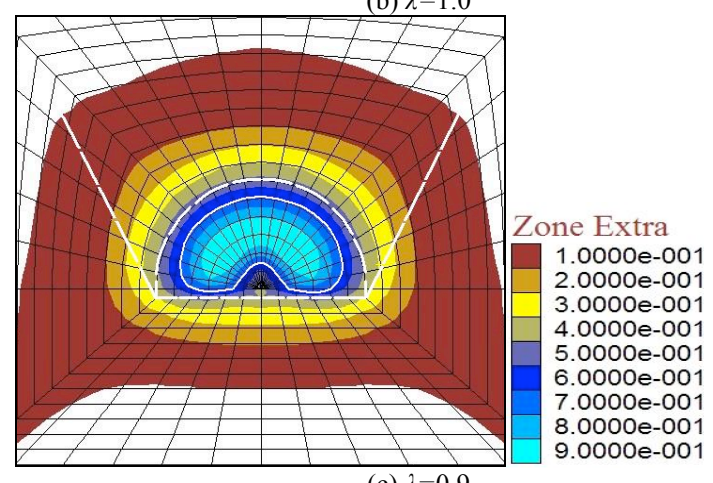

(c) $\lambda=0.9$

Fig.14. Pressure-arch distribution perpendicular to the tunnel axis under different stress states

\section{Conclusions}

Through the evolution characteristics analysis of the pressure-arch of a highway tunnel along the $y$-axis and perpendicular to the $y$-axis under different stress states, the conclusions can be obtained as follows:

With the change of the lateral pressure coefficient from small to large, the pressure-arch of the tunnel mainly was in three forms: the tensile stress appeared at the top of the tunnel, forming the partial pressure-arch $(\lambda<0.34)$; the pressure-arch approached to the tunnel working face, and the vault showed flat $(0.34<\lambda<1)$; the top pressure-arch of the tunnel uplifted upward $(\lambda>1)$, when $\lambda$ increased a certain value, the arch vault showed a bimodal distribution pattern.

With the principal stress difference near the tunnel working face increasing, the stability of the surrounding rock near the tunnel working face became worse and worse for the tunnel being excavated by step-by-step excavation along the $y$-axis. Relative to $\lambda>1$ or $\lambda<1$, when $\lambda=1$, the surrounding rock near the tunnel working face was likely to remain stable. 


\section{Acknowledgements}

This work was financially supported by the National Natural Science Foundation of China (51474188; 51074140; 51310105020), the Natural Science Foundation of Hebei Province of China (E2014203012), the International
Cooperation Project of Henan Science and Technology Department (162102410027), the Doctoral Fund of Henan Polytechnic University (B2015-67), and Program for Taihang Scholars. All these are gratefully acknowledged.

\section{References}

1. Polillo, A. F., Vassilellis, G. D., Graves, R. M., and Crafton, J. W., "Simulation of sand arching mechanics using an elasto-plastic finite element formulation", SPE Advanced Technology Series, 2(1), 1994, pp. 76-85.

2. Goel, R. K., Jethwa, J. L., and Dhar, B. B., "Effect of tunnel size on support pressure", International journal of rock mechanics and mining sciences \& geomechanics abstracts, 33(7), 1996, pp. 749755.

3. Prokhorov, I. Y., "Arch effect in high isostatic pressure compacts", Journal of the European Ceramic Society, 19(15), 1999, pp. 26192623.

4. Hashash, Y. M. A., and Whittle, A. J., "Mechanisms of load transfer and arching for braced excavations in clay", Journal of Geotechnical and Geoenvironmental Engineering, 128(3), 2002, pp. 187-197.

5. Shahin, H. M., Nakai, T., Hinokio, M., and Yamaguchi, D., “3D effects on earth pressure and displacements during tunnel excavations", Soils and Foundations, 44(5), 2004, pp. 37-49.

6. Hernández-Montes, E., Aschheim, M., and Gil-Martín, L. M., "The buried arch structural system for underground structures", Structural Engineering and Mechanics, 20(1), 2005, pp. 69-83.

7. Li, C. C., "Rock support design based on the concept of pressure arch", International Journal of Rock Mechanics and Mining Sciences, 43(7), 2006, pp. 1083-1090.

8. Poulsen, B. A., "Coal pillar load calculation by pressure arch theory and near field extraction ratio", International Journal of Rock Mechanics and Mining Sciences, 47(7), 2010, pp. 1158-1165.

9. Kim, K. Y, Lee, D. S., Cho, J., Jeong, S. S., and Lee, S., "The effect of arching pressure on a vertical circular shaft", Tunnelling and Underground Space Technology, 37, 2013, pp. 10-21.
10. Liu, T., Shen, M. R., Gao, W. J., and Tan D. Y., "Rock mass pressure release rate analysis for double-arch tunnel", Chinese Journal of Underground Space and Engineering, 3(1), 2007, pp. 50-54.

11. Zhu Z. G., Qiao, C. S., and Gao, B. B., “Analysis of construction optimization and supporting structure under load of shallow multiarch tunnel under unsymmetrical pressure", Rock and Soil Mechanics, 29(10), 2008, pp. 2747-2752.

12. Chen, C. N., Huang, W. Y., and Tseng, C. T., "Stress redistribution and ground arch development during tunneling", Tunnelling and Underground Space Technology, 26(1), 2011, pp. 228-235.

13. Jiang, M. J., and Yin, Z. Y., "Analysis of stress redistribution in soil and earth pressure on tunnel lining using the discrete element method", Tunnelling and Underground Space Technology, 32, 2012, pp. 251-259.

14. Yang, J. H., Wang, S. R., Wang, Y. G., and Li, C. L., "Analysis of Arching Mechanism and Evolution Characteristics of tunnel pressure-arch", Jordan Journal of Civil Engineering, 9(1), 2015, pp. $125-132$.

15. Li, Y., Zhe, L. R., Wei, Z., and Luo, L., "Experimental analysis of supporting structure of pressure to small spacing shallow bias tunnel in soft rock", Electronic Journal of Geotechnical Engineering, 19, 2014, pp. 4729-4741.

16. Sun, M. J., Hu, X. L., Tan, F. L., and Zhang, Y. M., "Status and progress of soil arching effect research", Electronic Journal of Geotechnical Engineering, 19, 2014, pp. 4293-4300.

17. Xing, X. K., Zhang, J. W., Teng, D. T., Liu, J., and Sun, G. X., "Experimental research on distribution regularity of the soil tunnel's pressure arch under different supporting stress", Chinese Journal of Underground Space and Engineering, 10(4), 2014, pp. 789-793. 